\title{
Article
}

\section{Synthesis of Mesoporous Silica@Co-Al Layered Double Hydroxide Spheres: Layer-by-Layer Method and Their Effects on the Flame Retardancy of Epoxy Resins}

Jiang, Shu-Dong, Bai, Zhi-Man, Tang, Gang, Song, Lei, Stec, Anna A, Hull, T Richard, Hu, Yuan and Hu, Wei-Zhao

Available at https://clok.uclan.ac.uk/11649/

Jiang, Shu-Dong, Bai, Zhi-Man, Tang, Gang, Song, Lei, Stec, Anna A orcid iconORCID: 0000-0002-6861-0468, Hull, T Richard orcid iconORCID: 00000002-7970-4208, Hu, Yuan and Hu, Wei-Zhao (2014) Synthesis of Mesoporous Silica@Co-Al Layered Double Hydroxide Spheres: Layer-by-Layer Method and Their Effects on the Flame Retardancy of Epoxy Resins. ACS Applied Materials \& Interfaces, 6 (16). pp. 14076-14086. ISSN 1944-8244

It is advisable to refer to the publisher's version if you intend to cite from the work. http://dx.doi.org/10.1021/am503412y

For more information about UCLan's research in this area go to http://www.uclan.ac.uk/researchgroups/ and search for <name of research Group>.

For information about Research generally at UCLan please go to http://www.uclan.ac.uk/research/

All outputs in CLoK are protected by Intellectual Property Rights law, including Copyright law. Copyright, IPR and Moral Rights for the works on this site are retained by the individual authors and/or other copyright owners. Terms and conditions for use of this material are defined in the policies page. 
Publication Information: Jiang, S.-D., Bai, Z.-M., Tang, G., Song, L., Stec, A.A., Hull, T.R., Hu, Y., Hu, W.-Z. Synthesis of mesoporous silica@Co-Al layered double hydroxide spheres: Layer-by-layer method and their effects on the flame retardancy of epoxy resins, ACS Applied Materials and Interfaces, 6 (16), pp.

14076-14086, (2014).

\title{
Synthesis of mesoporous silica@Co-Al layered double hydroxide spheres: layer-by-layer method and their effects on the flame retardancy of epoxy resins
}

Shu-Dong Jiang ${ }^{1}$, Zhi-Man Bai ${ }^{1,2}$, Gang Tang ${ }^{1}$, Lei Song ${ }^{1}$, Anna A Stec ${ }^{3}$, T. Richard Hull ${ }^{3}$, Yuan $\mathrm{Hu}^{1,2^{*}}$

\footnotetext{
${ }^{1)}$ State Key Laboratory of Fire Science, University of Science and Technology of China, 96 Jinzhai Road, Hefei, Anhui 230026, P. R. China.

${ }^{2)}$ Suzhou Key Laboratory of Urban Public Safety, Suzhou Institute for Advanced Study, University of Science and Technology of China, 166 Ren'ai Road, Suzhou, Jiangsu 215123, P. R. China.

3) Centre for Fire and Hazards Science, University of Central Lancashire, Preston PR1 2HE, United Kingdom.
}

${ }^{*}$ Corresponding author: Prof. Dr. Yuan $\mathrm{Hu}$

Tel: 8655163601664

Fax: 8655163601664

Email:yuanhu@ustc.edu.cn

\begin{abstract}

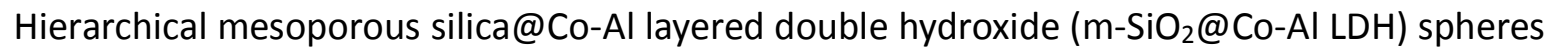
were prepared through a layer by layer assembly process, in order to integrate their excellent physical and chemical functionalities. TEM results depicted that, due to the electrostatic potential difference between $\mathrm{m}-\mathrm{SiO}_{2}$ and $\mathrm{Co}-\mathrm{Al} \mathrm{LDH}$, the synthetic m-SiO${ }_{2} @ \mathrm{Co}-\mathrm{Al}$ LDH hybrids exhibited that $\mathrm{m}-\mathrm{SiO}_{2}$ spheres were packaged by the Co-AI LDH nanosheets. Subsequently, the m-SiO ${ }_{2} @ \mathrm{Co}$-Al LDH spheres were incorporated into an epoxy resin (EP) matrix to prepare specimens for investigation of reduced fire hazard behavior. Cone results indicated that m-SiO ${ }_{2} @$ Co-Al LDH incorporated obviously improved fire retardant of EP. A plausible flame-retardant mechanism was speculated on the basis of the analyses of thermal conductivity, char residues and pyrolysis fragments. Labyrinth effect of $\mathrm{m}-\mathrm{SiO}_{2}$ and graphitized carbon char formation catalyzed by Co-AI LDH play key roles in the flame retardance enhancement.
\end{abstract}

Keywords: mesoporous silica@Co-Al layered double hydroxide spheres, layer-by-layer method, polymer composites, thermal stability, flame retardancy, mechanism 


\section{Introduction}

Mesoporous silica $\left(\mathrm{m}-\mathrm{SiO}_{2}\right)$ has attracted much interest for its widespread applications in molecular adsorption, catalysis, gas and biological sensors, due to its high surface area, tunable pore size and very narrow pore size distribution. ${ }^{1-3}$ The large-area and open-pore surface of $\mathrm{m}-\mathrm{SiO}_{2}$ is suitable for anchoring particles, trapping molecules, fast transport and optical manipulation. ${ }^{3-6}$ To date, $\mathrm{m}-\mathrm{SiO}_{2}$ has been further used to fabricate polymer nanocomposites with more excellent performance. ${ }^{7-9}$ Compared to other reported inorganic fillers, ${ }^{10-13}$ $\mathrm{m}-\mathrm{SiO}_{2}$ shows obvious advantages. On one hand, the mesopore sizes are much larger than the width of EP (about $0.5 \mathrm{~nm}$ ). Therefore, EP can be easily penetrated into the mesochannels due to capillary force. Also, EP wrapped by the surface of $\mathrm{m}-\mathrm{SiO}_{2}$ exhibits high thermal stability. On the other hand, unlike nanosheets and nanotubes, the one-dimensional mesopore space is randomly oriented inside the composites to endow isotropy for nanocomposites. ${ }^{14}$ Although $\mathrm{m}-\mathrm{SiO}_{2}$ is clearly a promising polymer additive, few studies have reported the new application of $\mathrm{m}-\mathrm{SiO}_{2}$ on the flame retardancy of polymers. ${ }^{15}$ Thus, broadening the application of $\mathrm{m}-\mathrm{SiO}_{2}$ is a promising avenue of research.

As a kind of important lamellar materials, layered double hydroxides are currently obtained intense research interest owning to their excellent physical and chemical properties, which result in their extensive applications in catalysis, adsorption and flame retardant. ${ }^{16-19}$ However, the use of layered double hydroxides alone remains unsatisfactory to meet specific requirements for applications. Recently, core-shell structured hybrids have received tremendous attention in recent research for the combined characteristics of cores and shells. Shao et al. provided a novel $\mathrm{Fe}_{3} \mathrm{O}_{4} @ \mathrm{SiO}_{2} @ \mathrm{NiAl}-\mathrm{LDH}$ for the practical purification of recombinant proteins. ${ }^{20}$ Silica microspheres decorated with CdS nanocrystals were synthesized by a facile process and used for the physical adsorption and direct photolysis of $\mathrm{N}$-containing dyes. ${ }^{21}$ Teng et al. reported the fabrication of $\mathrm{Fe}_{3} \mathrm{O}_{4} @ \mathrm{SiO}_{2}$ with superparamagnetism, high magnetization and large surface area. ${ }^{22}$ Inspired by these, this study aims to combine of $\mathrm{m}-\mathrm{SiO}_{2}$ and Co-Al layered double hydroxide (Co-Al LDH) to improve their flame retardancy effectiveness. Co-Al LDH is a well-investigated member of the LDH family due to its ease of synthesis and delamination. ${ }^{23}$ The exfoliated single sheets of Co-Al layered double hydroxide (Co-AI LDH) is positively charged with a thickness of $0.8 \mathrm{~nm} \cdot{ }^{24} \mathrm{It}$ is known that the surface of $\mathrm{m}-\mathrm{SiO}_{2}$ is negatively charged above the isoelectric point, which favors a layer coating of the positively charged material. ${ }^{25}$ Electrostatic interactions between negatively charged $\mathrm{m}-\mathrm{SiO}_{2}$ and positively charged LDH sheets can create layered structures on the surface of $\mathrm{m}-\mathrm{SiO}_{2}$ through a layer-by-layer assembly method.

EP is one of the most widely exploited reactive polymeric resins in laminating, adhesive, coating and casting fields. ${ }^{26-27}$ However, its high flammability greatly restricted its application in some areas. Herein, m-SiO ${ }_{2} @ \mathrm{Co}-\mathrm{Al}$ LDH spheres were synthesized by ultrasound assisted direct layered assembly of Co-AI LDH nanosheets on the surface of $\mathrm{m}-\mathrm{SiO}_{2}$ spheres, as schematically depicted in Scheme 1. Subsequently, the m-SiO ${ }_{2} @ \mathrm{Co}-\mathrm{Al}$ LDH spheres were incorporated into 
an EP matrix to prepare specimens for investigation of reduced fire hazard behavior. The synergistic effect between $\mathrm{m}-\mathrm{SiO}_{2}$ and $\mathrm{Co}-\mathrm{Al} \mathrm{LDH}$ on the thermal stability and fire resistance of the as-prepared nanocomposite was systematically investigated using thermogravimetric analysis (TGA) and cone calorimetry. Meanwhile, the analyses of thermal conductivity, char residue and pyrolysis fragments were utilized in an attempt to gain insight into flame-retardant mechanism.

Scheme 1. The synthetic route of m-SiO ${ }_{2} @ \mathrm{Co}-\mathrm{Al}$ LDH.

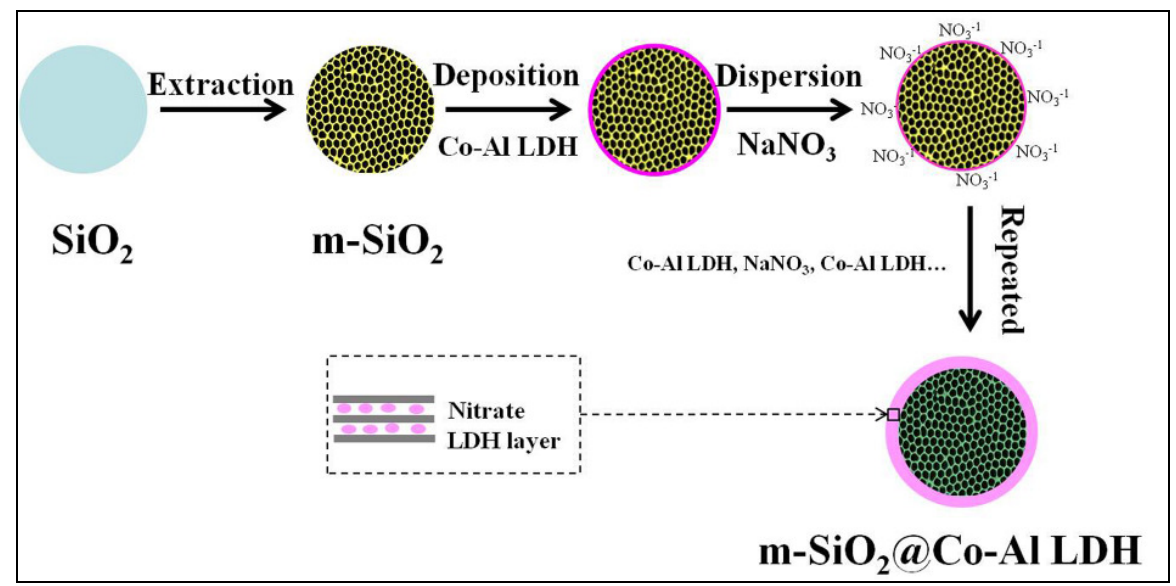

\section{Experimental}

Tetraethyl orthosilicate (TEOS), cetyl trimethyl ammonium bromide (CTAB), ammonium hydroxide (28\%), ethanol, $\mathrm{Co}\left(\mathrm{NO}_{3}\right)_{2} \cdot 6 \mathrm{H}_{2} \mathrm{O}, \mathrm{Al}\left(\mathrm{NO}_{3}\right)_{3} \cdot 9 \mathrm{H}_{2} \mathrm{O}, \mathrm{NaNO}_{3}$, tetrahydrofuran (THF) 4,4'-diaminodiphenylmethane (DDM) were purchased from Sinopharm Chemical Reagent Co., Ltd. (Shanghai, China). Bisphenol-A type epoxy resin was commercially supplied by Hefei Jiangfeng Chemical Industry Co., Ltd., China.

\subsection{Preparation of $\mathrm{m}$-SiO2}

$\mathrm{m}-\mathrm{SiO}_{2}$ spheres were synthesized through a modified Stöber method. Typically, CTAB was dissolved in ethanol aqueous solution containing ammonium hydroxide. Then, TEOS (1 mL) was quickly injected into the above solution at $45^{\circ} \mathrm{C}$ under strong mechanical stirring at a speed of $1500 \mathrm{rpm}$. The reactant molar ratio was 1.00 TEOS:0.0954 CTAB:2.84 NH $\mathrm{NH}_{3}: 723 \mathrm{H}_{2} \mathrm{O}: 125 \mathrm{C}_{2} \mathrm{H}_{5} \mathrm{OH}$. After $24 \mathrm{~h}$ of thermostatic reaction, the white precipitate was isolated by centrifugation at 5000 rpm for $10 \mathrm{~min}$ and cleaned by three cycles of centrifugation/washing/redispersion in ethanol. The yield of the final product was about $70 \%$.

\subsection{Preparation of Co-AI LDH}

Co-AI LDH was prepared by a slow co-precipitation followed by ultrasound treatment. Briefly, $0.8 \mathrm{~mL}$ of aqueous ammonia solution $(12.3 \mathrm{mmol}$ ) was added into $20 \mathrm{~mL}$ of deionized water to form solution $A$. Then $19.2 \mathrm{~mL}$ of an aqueous solution containing $0.96 \mathrm{mmol}$ of $\mathrm{Co}\left(\mathrm{NO}_{3}\right)_{2} \cdot 6 \mathrm{H}_{2} \mathrm{O}$ 
and $0.48 \mathrm{mmol}$ of $\mathrm{Al}\left(\mathrm{NO}_{3}\right)_{3} \cdot 9 \mathrm{H}_{2} \mathrm{O}$ was dropped at a constant rate of $40 \mathrm{~mL} / \mathrm{h}$ into solution $\mathrm{A}$ under vigorous mechanical stirring with a speed of $2000 \mathrm{rpm}$ (JJ-1 motor stirrer, 60W, $3000 \mathrm{rpm}$, Changzhou saipu Instruments Equipment Co., Ltd., China) followed by ultrasonication for $1 \mathrm{~h}$. For the ultrasonication, this was done with a typical immersion bath. The model sonic bath was KQ-250 with a frequency of $40 \mathrm{KHz}$ ( Gongyi yuhua Instruments Equipment Co. , Ltd., China).The obtained solid was collected and washed with pure water and ethanol. The yield of the Co-Al LDH was about $80 \%$

\subsection{Preparation of $m$-SiO2@Co-Al LDH through the layer-by-layer method}

$\mathrm{m}-\mathrm{SiO}_{2}(0.5 \mathrm{~g})$ was dispersed in a Co-Al LDH formamide solution $(0.1 \mathrm{~g} / 100 \mathrm{~mL})$. Then, the mixture was ultrasonically agitated for $20 \mathrm{~min}$ to facilitate the adsorption of Co-AI LDH nanosheets onto the $\mathrm{m}-\mathrm{SiO}_{2}$ surface. The particles were collected by centrifugation at $6000 \mathrm{rpm}$ for $10 \mathrm{~min}$ and washed with deionized water. In the next step, the particles were dispersed in a $\mathrm{NaNO}_{3}$ solution $(100 \mathrm{~mL}, 2 \mathrm{~g} / \mathrm{L}$ ). The pink precipitate was isolated by centrifugation ( $6000 \mathrm{rpm}$, $10 \mathrm{~min}$ ). $\mathrm{m}-\mathrm{SiO}_{2}$ coated with 10 layer pairs of nitrate and $\mathrm{LDH}$ nanosheets $\left(\mathrm{NO}_{3}{ }^{-1} / \mathrm{LDH}\right)_{10}$ were prepared through repeating the above procedures 10 times. The yield of the final product was about $90 \%$.

\subsection{Preparation of EP/m-SiO2@Co-Al LDH composite}

A typical preparation of epoxy composite containing 2 wt\% m-SiO ${ }_{2} @ \mathrm{Co}-\mathrm{Al}$ LDH is illustrated below: m-SiO ${ }_{2} @ \mathrm{Co}-\mathrm{Al}$ LDH $(0.2 \mathrm{~g})$ was added in THF with ultrasonication (Immersion sonic bath, KQ-250, $40 \mathrm{KHz}$, Gongyi yuhua Instruments Equipment Co. , Ltd., China) to form a pink suspension. Then, DDM $(1.6 \mathrm{~g})$ was melt at $95^{\circ} \mathrm{C}$ and mixed with epoxy resin $(8.2 \mathrm{~g})$ by hand with a spatula for $10 \mathrm{~min}$. Subsequently, the mixture of epoxy resin and DDM was poured into the above suspension under magnetic stirring with a speed of $1000 \mathrm{rpm}$ for $30 \mathrm{~min}$ until a homogeneous mixture was formed. The mixture was placed in a vacuum chamber at $60^{\circ} \mathrm{C}$ for $12 \mathrm{~h}$ to remove THF. Finally, the EP/m-SiO ${ }_{2} @ \mathrm{Co}-\mathrm{Al} \mathrm{LDH}$ composite was cured at $100{ }^{\circ} \mathrm{C}$ for $2 \mathrm{~h}$ and post cured at $150^{\circ} \mathrm{C}$ for $2 \mathrm{~h}$. After curing, the composite was permitted to cool to room temperature. For the preparation of neat EP, EP/Co-Al LDH and EP/m-SiO ${ }_{2}$ composites, a analogous prepared procedure was adopted except the variation of the additives.

\subsection{Characterization}

Powder X-ray diffraction (XRD) measurements were performed on a Japan Rigaku DMax/rA rotating anode $X$-ray diffractometer, using $\mathrm{Cu} K \alpha$ radiation $(\lambda=0.154 \mathrm{~nm})$ at $40 \mathrm{kV}$. Transmission electron microscopy (TEM), Energy dispersive $X$-ray spectroscopy (EDX) and high-resolution transmission electron microscopy (HRTEM) analyses were performed using a Hitachi model H-800 TEM with an accelerating voltage of $200 \mathrm{kV}$. Before measurement, samples were dispersed in ethanol followed by ultrasonication for $30 \mathrm{~min}$ at room temperature. The homogeneous mixtures were dripped on carbon-coated copper grids. UV-vis absorption spectra were detected by a Solid 3700 (SHIMADZU) spectrometer. X-ray photoelectron spectroscopy (XPS) spectra were recorded on an ESCALAB $250 \mathrm{X}$-ray photoelectron spectrometer employing a monochromatic AI Ka X-ray source. Thermogravimetric analyses (TGA) of samples were implementing with the aid of a Q5000 thermal analyzer (TA Co., USA) at a heating speed of $20^{\circ} \mathrm{C} \mathrm{min}^{-1}$ in nitrogen atmosphere. The combustion properties of EP and EP 
composites were carried out on a cone calorimeter based on ASTM E1354/ISO 5660. Every specimen with the sizes of $100 \times 100 \times 3 \mathrm{~mm}^{3}$ wrapped in an aluminum foil was exposed horizontally to a heat flux of $35 \mathrm{~kW} / \mathrm{m}^{2}$. Three parallel runs were performed for each sample to obtain averages. Microstructures of the char residues were studied by a JEOL JSM-2010 field-emission scanning electron microscopy (FESEM). Raman spectroscopy measurements were carried out with a SPEX-1403 laser Raman spectrometer (SPEX Co, USA) with excitation provided in back-scattering geometry by a $514.5 \mathrm{~nm}$ argon laser line. Direct pyrolysis-mass spectrometry (DP-MS) analysis was performed with a Micromass GCT-MS spectrometer using the standard direct insertion probe for solid polymer materials, at a heating rate of $15^{\circ} \mathrm{C} \mathrm{min}^{-1}$ in the range of $30-700^{\circ} \mathrm{C}$.

\section{Result and Discussion}

\subsection{Characterization of m-SiO2@Co-Al LDH}

TEM image in Figure $1 \mathrm{~A}$ shows that $\mathrm{m}-\mathrm{SiO}_{2}$ spheres are monodispersed with a uniform diameter of around $500 \mathrm{~nm}$. High-magnification TEM image depicts that the mesochannels of the spheres are continuous throughout the shell with openings at surface and are radially oriented to the sphere surface (Figure 1B), which can absorb EP molecular chain. The surface of $\mathrm{m}-\mathrm{SiO}_{2}$ spheres is negatively charged as indicated by a zeta potential of $-45 \mathrm{mV}$. Hence, deposition of the oppositely charged Co-AI LDH precursors via electrostatic interaction can easily occur without adding any additives or binding agents. The morphology of m-SiO ${ }_{2} @ \mathrm{Co}-\mathrm{Al}$ LDH was further examined by TEM (Figures $2 \mathrm{C}, \mathrm{D}$ and $\mathrm{E}$ ). It can be observed that the final composite consists of well dispersed spheres with an average diameter of around $550 \mathrm{~nm}$. The surface of $\mathrm{m}-\mathrm{SiO}_{2}$ spheres (dark colour) is coated with a layer of lighter coloured LDH nanosheets. As shown in Figure $1 \mathrm{~F}$, the building block of nanosheets shows a repeating fringe of $\sim 0.8 \mathrm{~nm}$. They are assembled with a face-to-face stacking to form a layer structure with a lateral scale of $8 \mathrm{~nm}$. The zeta potential of m-SiO ${ }_{2} @$ Co-Al LDH was measured to be $+26.7 \mathrm{mV}$, further supporting that positively charged LDH nanosheets have been effectively coated on the surface of $\mathrm{m}-\mathrm{SiO}_{2}$. The existence of Co-Al LDH coating on the surface of $\mathrm{m}-\mathrm{SiO}_{2}$ was also identified by EDX, as shown in Figure 1G. 

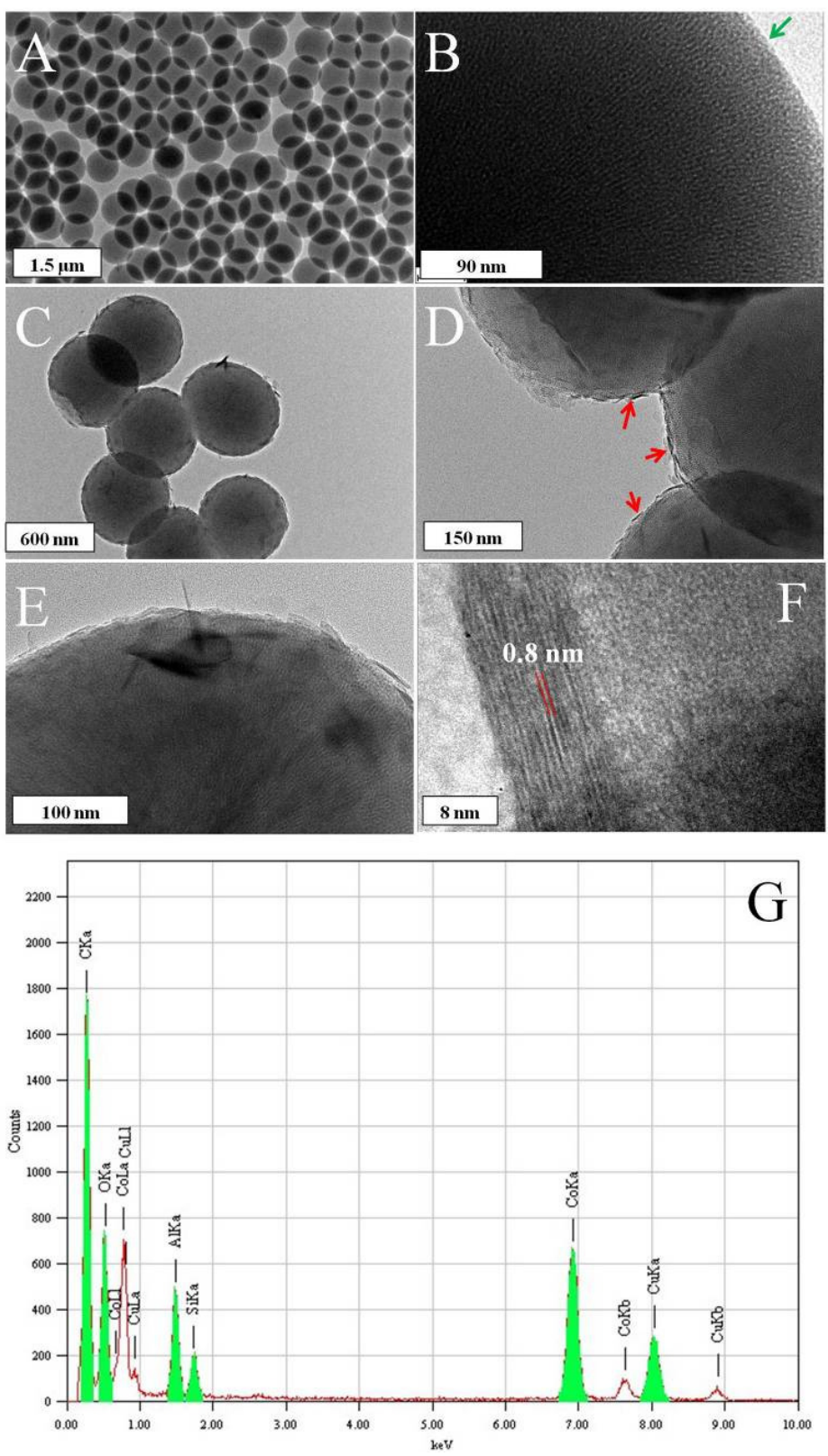

Figure 1. TEM images of $m-\mathrm{SiO}_{2}(\mathrm{~A}, \mathrm{~B}), \mathrm{m}-\mathrm{SiO}_{2} @ \mathrm{Co}-\mathrm{Al} \mathrm{LDH}(\mathrm{C}, \mathrm{D}, \mathrm{E}), \mathrm{HRTEM}$ image (F) of m-SiO ${ }_{2} @$ Co-Al LDH and EDX spectra (G) of m-SiO ${ }_{2} @ C o-A l$ LDH.

As far as the layer number is concerned, the morphology of samples appears nearly same. For the blank $\mathrm{m}-\mathrm{SiO}_{2}$, the particles exhibit microspheres with a smooth surface (Figure $2 \mathrm{~A}$ ). With the layer number increased to 10 , the spherical morphology of monodisperse $\mathrm{m}$ - $\mathrm{SiO}_{2}$ spheres is preserved well after the deposition of nitrate LDH shell (Figure $2 \mathrm{~B}$ ). The only noticeable difference between the spheres with or without shells is the surface roughness. When the layer number is increased to 20, the surface of $\mathrm{SiO}_{2}$ spheres (dark colour) is coated with more LDH 
nanosheets and become more coarser (Figure 2C). Moreover, there is an enhanced absorbance at $\lambda=525 \mathrm{~nm}$ (Figure 2D) with the increase of the layer number, which is in accordance with the color change of the samples.

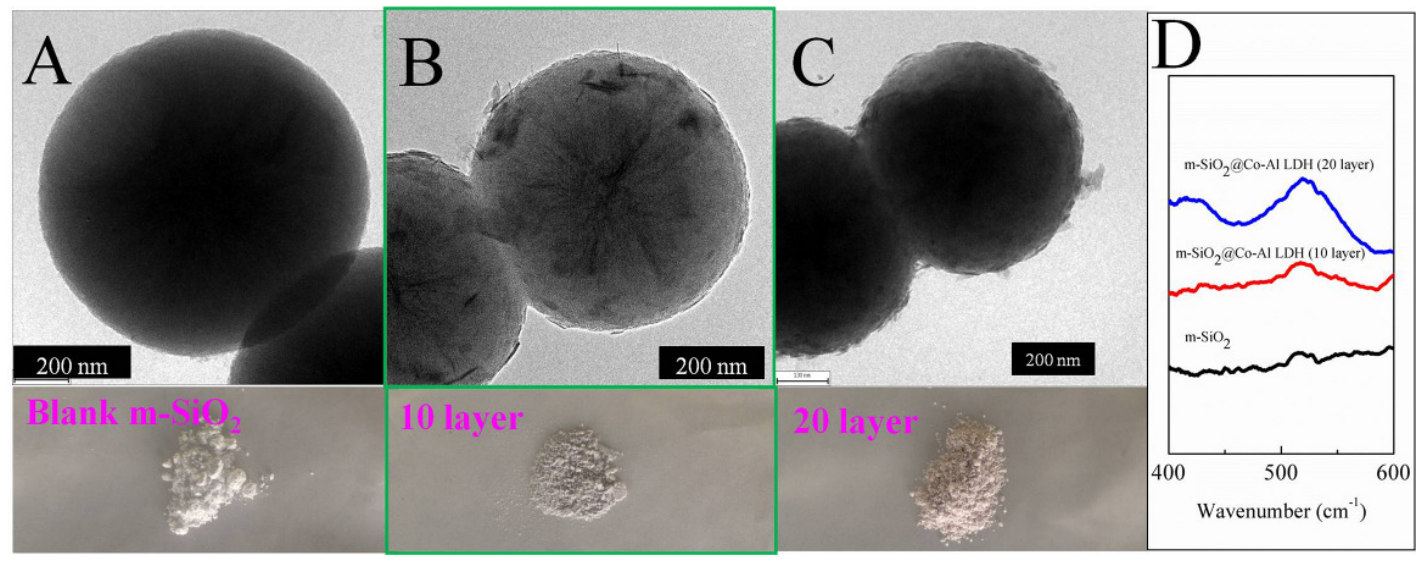

Figure 2. TEM images, digital photos $(A, B, C)$ and UV-vis absorption spectra (D) of $\mathrm{m}-\mathrm{SiO}_{2}$, m-SiO ${ }_{2} @$ Co-Al LDH (10 layers) and m-SiO ${ }_{2} @$ Co-Al LDH (20 layers).

The composition and structure of $\mathrm{m}-\mathrm{SiO}_{2}, \mathrm{Co}-\mathrm{Al}$ LDH and $\mathrm{m}-\mathrm{SiO}_{2} @ \mathrm{Co}-\mathrm{Al}$ LDH were identified by XRD, as shown in Figure 3. The wide-angle XRD pattern of $\mathrm{m}-\mathrm{SiO}_{2}$ shows a broad peak around $21^{\circ}$, revealing its amorphous nature. ${ }^{28}$ For Co-Al LDH, all diffraction peaks can be indexed as Co-Al LDH. ${ }^{29-30}$ The broadened diffraction peaks of Co-Al LDH indicate that the synthetic sample is composed of nanocrystals. ${ }^{31}$

Compared the $\mathrm{m}-\mathrm{SiO}_{2}, \mathrm{Co}-\mathrm{Al} \mathrm{LDH}$ and $\mathrm{m}-\mathrm{SiO}_{2} @ \mathrm{Co}-\mathrm{Al} \mathrm{LDH}$ wide-angle XRD patterns, two relatively weak peaks of m-SiO $@$ @Co-Al LDH at around can be assigned to (003) and (012) of layered Co-Al LDH structure (Figure 3A). Moreover, the (006) peak of Co-Al LDH and the broad peak between $20^{\circ}$ and $25^{\circ}$ of $\mathrm{m}-\mathrm{SiO}_{2}$ were overlapping, so the broad peak of $\mathrm{m}-\mathrm{SiO}_{2}$ may cover the weak (006) peak of Co-Al LDH in the

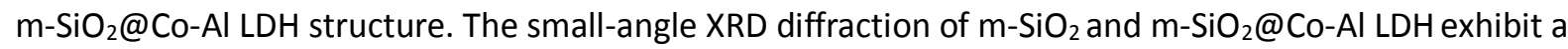
typical diffraction pattern of hexagonally packed mesopores, associated with the 100, 110, and 200 reflections of hexagonal symmetry with the space group p6mm (Figure 3B). This is in good agreement with that of the as-made bulk mesoporous silica MCM-41, suggesting a similar ordered hexagonal mesostructure. ${ }^{32}$ The $d_{100}$ spacing of the mesostructure is $3.7 \mathrm{~nm}$, corresponding to a unit cell parameter of $4.3 \mathrm{~nm}$. Nitrogen sorption isotherm of the m-SiO ${ }_{2} @ \mathrm{Co}-\mathrm{Al} \mathrm{LDH}$ spheres depicts a type IV curve according to the IUPAC nomenclature with a sharp capillary condensation step and a hysteresis loop in the $p / p_{0}$ range $0.2-0.4$ (Figure $3 C$ ), revealing characteristics of mesoporous materials with narrow pore size distribution. The surface area and pore volume are calculated to be as high as about $1020 \mathrm{~m}^{2} \mathrm{~g}^{-1}$ and $0.80 \mathrm{~cm}^{3} \mathrm{~g}^{-1}$. The detailed pore size distribution calculated based on the nonlocal density functional theory reveals the spheres have uniform micropores of about $1.2 \mathrm{~nm}$ (Figure 3D).

XPS analysis was used to investigate the surface composition and chemical state of the m-SiO ${ }_{2} @ \mathrm{Co}-\mathrm{Al}$ LDH spheres, which could provide information of the interaction between $\mathrm{m}-\mathrm{SiO}_{2}$ and Co-Al LDH. In Figure 4A it can be seen that the product contains $\mathrm{Si}, \mathrm{O}$, Co and Al elements, indicating the formation of $\mathrm{m}-\mathrm{SiO}_{2} @ \mathrm{Co}-\mathrm{Al}$ LDH. The $\mathrm{Co}_{2 p}$ spectrum is shown in Figure 4B. Two peaks corresponding to $\mathrm{Co}_{2} \mathrm{p}_{3 / 2}$ and $\mathrm{Co} 2 \mathrm{p}_{1 / 2}$ are centered at $781.2 \mathrm{eV}$ and $796.8 \mathrm{eV}$, respectively. The Co2 $\mathrm{p}_{3 / 2}$ peak of m-SiO $\mathrm{S}_{2} @ \mathrm{Co}-\mathrm{Al}$ LDH appears at higher position than that of normal Co-Al 
LDH, indicating a stronger interaction between silica shell and Co-Al LDH species. ${ }^{33-35}$ The presence of $\mathrm{m}-\mathrm{SiO}_{2}$ can also be clearly confirmed from the Si2p curve (Figure $4 \mathrm{C}$ ). The position of $102.06 \mathrm{eV}$ compares well with literature reports on binding energies for $\mathrm{SiO}_{2}$. Furthermore, a dark-field scanning transmission electron microscopy (STEM) analysis of m-SiO ${ }_{2} @$ Co-Al LDH was performed to obtain more detailed information about the structure. As shown in Figure 4D, the dark-field STEM clearly demonstrates that the as-synthesized m-SiO ${ }_{2} @$ Co-Al LDH have a typical core-shell structure, and EDX element mapping of the same particles further shows the spatial distributions of $\mathrm{Si}, \mathrm{O}, \mathrm{Co}$ and $\mathrm{Al}$ in nanoparticles of $\mathrm{m}-\mathrm{SiO}_{2} @ \mathrm{Co}-\mathrm{Al} \mathrm{LDH}$. The strong Si and $\mathrm{O}$ signal across the sphere confirms the $\mathrm{m}^{-\mathrm{SiO}_{2}}$ core, while the $\mathrm{Co}$ and $\mathrm{Al}$ signals both detected in the surface region clearly suggests the adsorption of Co-AI LDH particles.
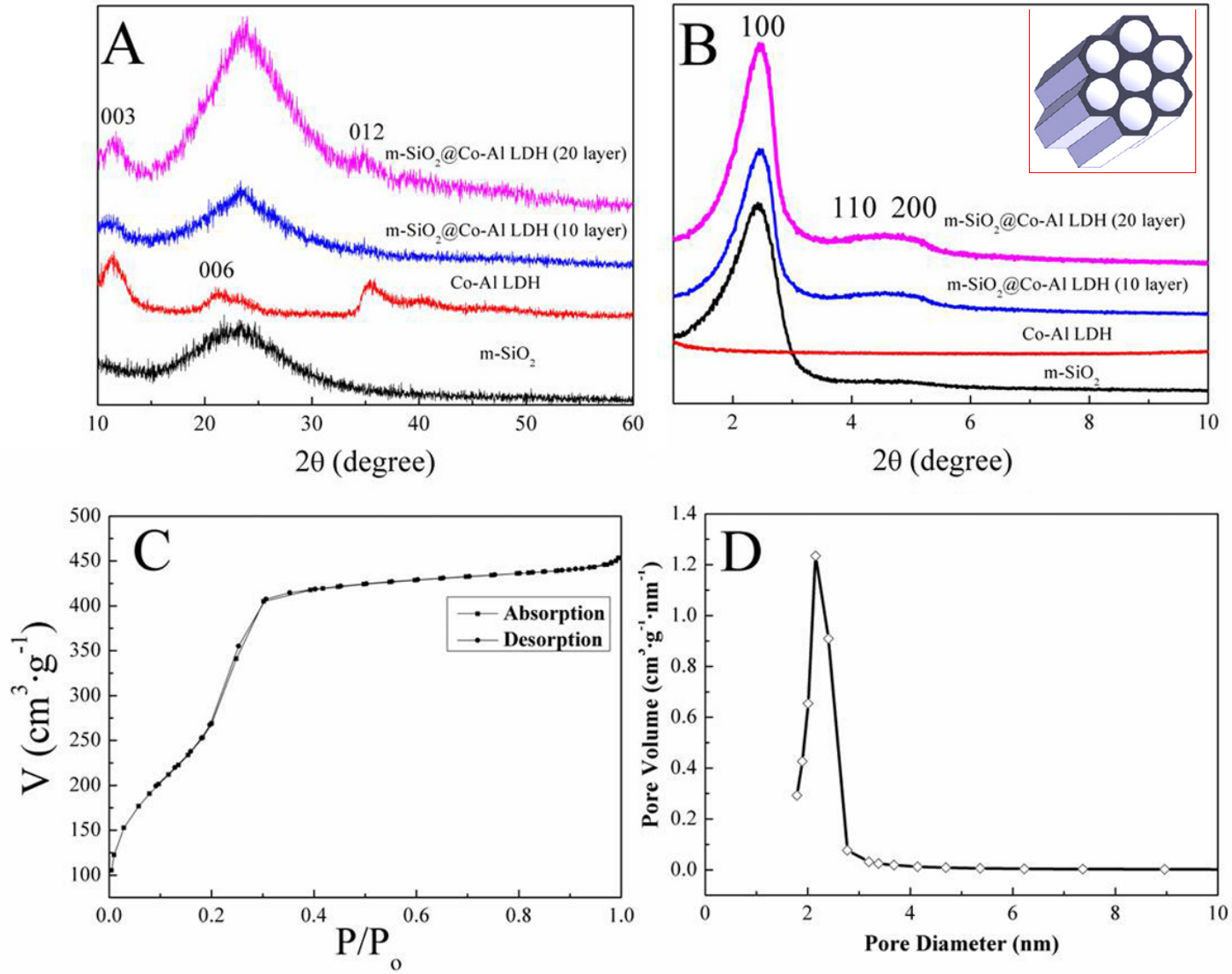

Figure 3. The wide-angle XRD pattern (A) and the low-angle XRD pattern (B) m-SiO $@ @ C o-A I L D H$, nitrogen sorption isotherm $(C)$ and the pore size distribution curve of $m-\mathrm{SiO}_{2} @ \mathrm{Co}-\mathrm{Al}$ LDH (D). Inset in (B) is a structural model of the mesoporous silica shells, showing hexagonal symmetry. 

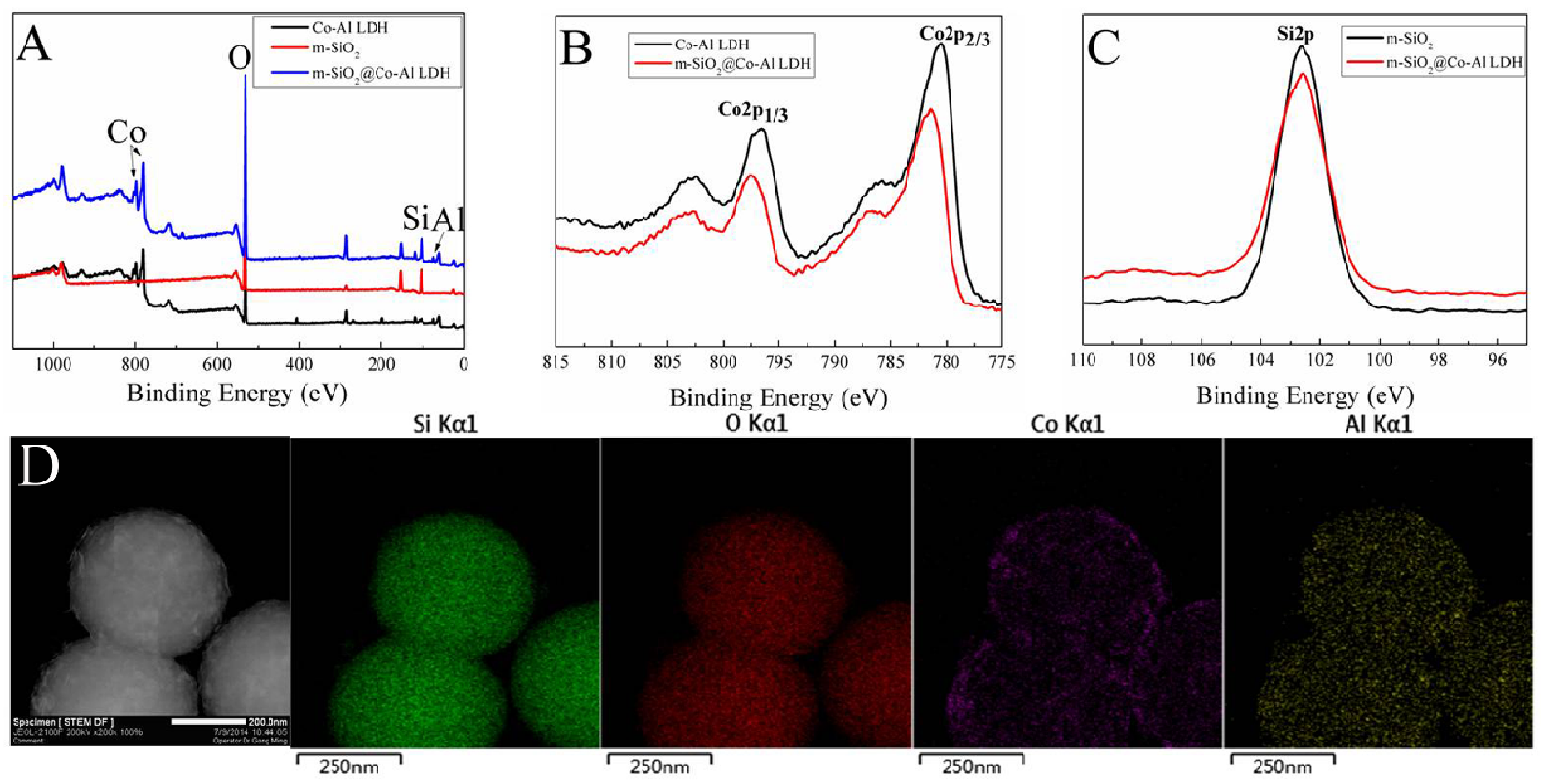

Figure 4. XPS survey spectra of Co-AI LDH, m-SiO 2 and m-SiO ${ }_{2} @ \mathrm{Co}-\mathrm{Al}$ LDH (A), Co2p XPS spectra of Co-Al LDH and m-SiO ${ }_{2} @ \mathrm{Co}-\mathrm{Al}$ LDH (B), Si2p XPS spectra of m-SiO ${ }_{2}$ and m-SiO ${ }_{2} @ \mathrm{Co}-\mathrm{Al}$ LDH (C), dark-field STEM image and elemental mapping of m-SiO ${ }_{2} @$ Co-Al LDH (D).

\subsection{Thermal degradation of EP and its nanocomposites}

The thermal stability of m-SiO ${ }_{2}, \mathrm{Co}-\mathrm{Al}$ LDH, m-SiO ${ }_{2} @ \mathrm{Co}-\mathrm{Al}$ LDH, EP and its nanocomposites was evaluated by TGA in nitrogen atmosphere. Figure 5 shows the TGA and derivative thermogravimetric (DTG) curves, and the corresponding data are given in Table 1 . The temperatures at which $10 \%\left(\mathrm{~T}_{-10 \%}\right), 50 \%\left(\mathrm{~T}_{-50 \%}\right)$ and maximum $\left(\mathrm{T}_{\max }\right)$ mass loss occurs are used as the measure of initial degradation temperature, half degradation temperature and maximum degradation temperature, respectively. Pure $\mathrm{m}-\mathrm{SiO}_{2}$ shows a three-step thermogravimetric profile corresponding to the loss of physically adsorbed water (room temperature $-120^{\circ} \mathrm{C}$ ), the polycondensation of the silica network $\left(120-210^{\circ} \mathrm{C}\right)$ and the further condensation and dehydration of silanol groups $\left(210-350^{\circ} \mathrm{C}\right) .{ }^{36-38} \mathrm{Co}-\mathrm{Al}$ LDH exhibits a three-step thermogravimetric profile accompanied a mass loss of about $34.3 \%$, which should be due to surface-adsorbed water (from room temperature to $200^{\circ} \mathrm{C}$ ), chemisorbed water $\left(200-350{ }^{\circ} \mathrm{C}\right.$ ) and the water arising from the dehydroxylation of the layers $\left(225-500{ }^{\circ} \mathrm{C}\right) .{ }^{19}$ In comparison, m-SiO ${ }_{2} @$ Co-Al LDH displays a consecutive mass loss with a weight loss of about $14.3 \%$, implying that the integration of $\mathrm{Co}-\mathrm{Al} \mathrm{LDH}$ with $\mathrm{m}-\mathrm{SiO}_{2}$ obviously enhances the thermal stability of Co-Al $\mathrm{LDH}$. Form Figure 5 and Table $1, \mathrm{EP} / \mathrm{m}-\mathrm{SiO}_{2}$ nanocomposite is less thermally stable than pure EP when evaluated by $T_{-10 \%}$, which is possibly attribute to the catalysis degradation initiated by silanol groups attached on $\mathrm{m}-\mathrm{SiO}_{2}$ as brønsted acid sites. ${ }^{39}$ At higher temperatures, the EP molecular chains encapsulated by the silica walls shows high thermal stability due to the barrier effect of its porous structure, leading to a delayed degradation process of EP. ${ }^{40}$ It is already known that transition metals including Co can cause catalytic degradation of polymer. ${ }^{41}$ As expected, the Co-AI LDH incorporated results in an earlier degradation process of EP. Also, the 
introduction of m-SiO ${ }_{2} @ \mathrm{Co}-\mathrm{Al}$ LDH leads to the decrease of degradation temperature, which is attributable to the earlier degradation of EP triggered by the catalytic activity of Co-AI LDH. However, compared to EP/Co-Al LDH,EP/m-SiO ${ }_{2} @ \mathrm{Co}-\mathrm{Al}$ LDH nanocomposite presents the improved thermal stability owning to the barrier effect of $\mathrm{m}-\mathrm{SiO}_{2}$. As far as the char yield is concerned, the incorporation of Co-Al LDH or m-SiO ${ }_{2} @ \mathrm{Co}-\mathrm{Al}$ LDH leads to the increase of the char residues at $700{ }^{\circ} \mathrm{C}$, due to the catalytic carbonization effect of $\mathrm{LDH} .{ }^{42}$ Additionally, from the DTG profiles, the maximum mass loss rates (the peak of DTG curve) of $\mathrm{EP} / \mathrm{m}-\mathrm{SiO}_{2}$ and $\mathrm{EP} / \mathrm{m}-\mathrm{SiO}_{2} @ \mathrm{Co}-\mathrm{Al}$ LDH composites are much lower than that of pure EP, indicating that $\mathrm{m}-\mathrm{SiO}_{2}$ plays an effective mass-transport barrier role.
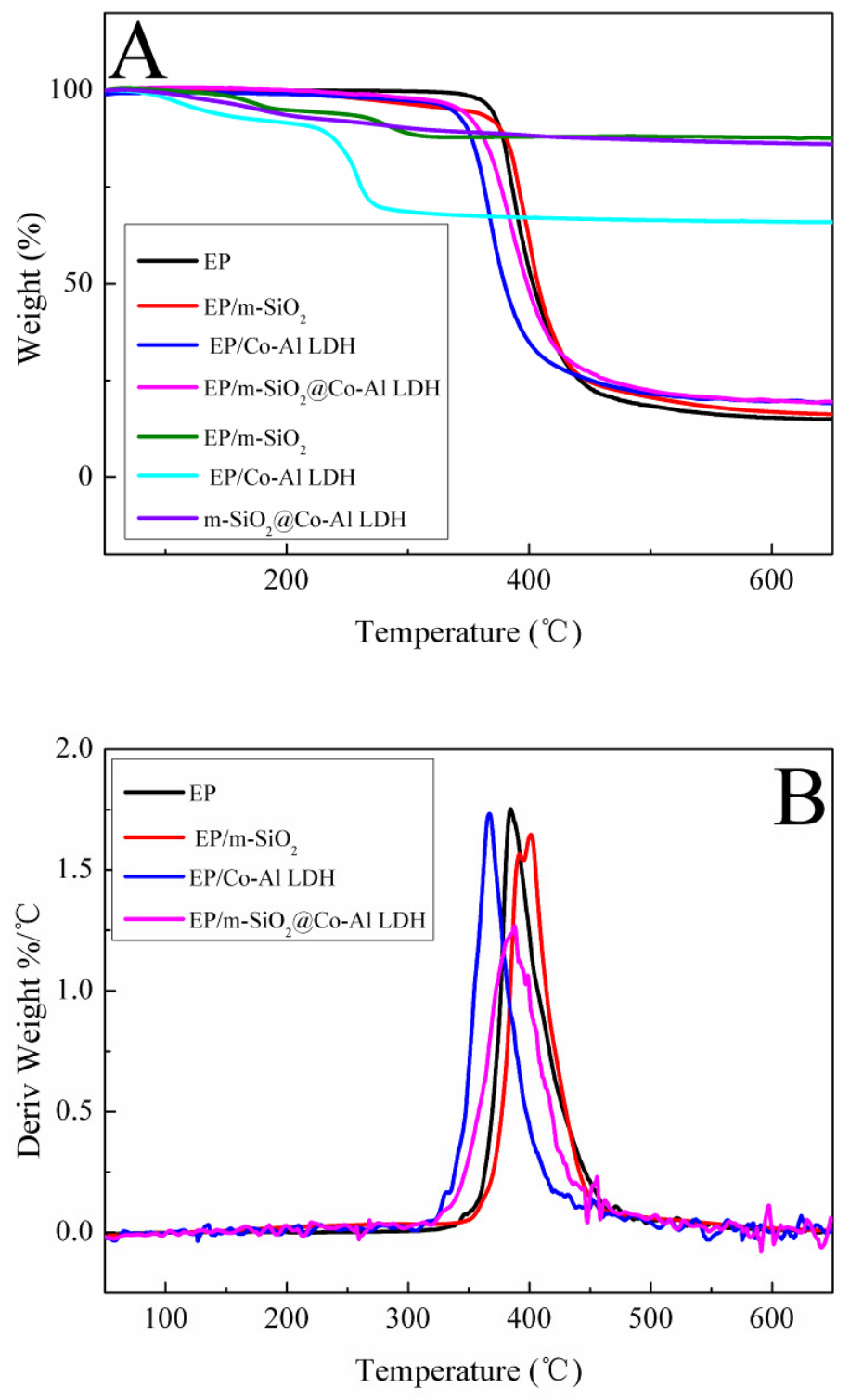

Figure 5. TGA (A) and DTA (B) curves of pure EP and its nanocomposites in nitrogen. 
Table 1. TGA data for EP and its nanocomposites in nitrogen.

\begin{tabular}{l|llll}
\hline Sample & $T_{-10 \%}\left({ }^{\circ} \mathrm{C}\right)$ & $\left.T_{-50 \%}\left({ }^{\circ} \mathrm{C}\right)\right)$ & $\left.T_{\max }\left({ }^{\circ} \mathrm{C}\right)\right)$ & Char (\%) \\
\hline EP & 376.0 & 403.2 & 385.2 & 14.7 \\
EP/m-SiO 2 & 376.4 & 407.1 & 401.8 & 15.8 \\
EP/Co-Al LDH & 349.0 & 379.6 & 366.5 & 18.4 \\
EP/m-SiO $@$ Co-Al LDH & 358.1 & 398.3 & 389.1 & 19.0 \\
\hline
\end{tabular}

\subsection{Fire properties of EP and its composites}

Cone calorimetry is a widely used tool for investigating flammability of materials to forecast fire behaviour in real-world fire. ${ }^{43}$ Heat release rate (HRR) curves for EP and its composites are shown in Figure 6 and some important parameters obtained from cone calorimetry are listed in Table $2 \mathrm{With}$ the incorporation of inorganic additives, the peak heat release rate (pHRR), total heat release (THR), effective heat of combustion (EHC), total smoke release (TSR) and maximum average heat rate emission (MAHRE) values are shifted to lower values except that the THR value of $\mathrm{EP} / \mathrm{m}-\mathrm{SiO}_{2}$ increases. This phenomenon is attributed to the prolonged burning time as can be seen from the broad peak width in the pHRR curve and the formation of the combustible fragment from the catalytic degradation effect of $\mathrm{m}-\mathrm{SiO}_{2} \cdot{ }^{44-47}$ Compared to pure $\mathrm{EP}$, the addition of $\mathrm{m}-\mathrm{SiO}_{2} @ \mathrm{Co}-\mathrm{Al}$ LDH brings about a 39.3\% maximum decrease in pHRR, a 36.2\% maximum decrease in THR, a 15.8\% maximum decrease in EHC, a 23.8\% maximum decrease in TSR and a $16.7 \%$ maximum decrease in MAHRE. The results exhibit that the EP/m-SiO $@$ @Co-Al LDH nanocomposite presents the best flame retardancy among all the nanocomposites. According to the earlier literatures, $\mathrm{m}-\mathrm{SiO}_{2}$ has an interconnected porous structure with low thermal conductivity. ${ }^{48}$ Heat and mass transport pathways in such a pore structure are long and tortuous, resulting in the diffusion of heat and the emission of volatile degradation products restricted. Thus, the labyrinth effects from $\mathrm{m}-\mathrm{SiO}_{2}$, containing mass barrier and thermal barrier effects, are hypothesized to be the main reasons for the flame retardancy enhancement. The thermal barrier effect limits the permeation of heat; meanwhile the mass barrier effect inhibits the escape of degradation products. In addition, the improved char yield of EP/m-SiO ${ }_{2} @ \mathrm{Co}-\mathrm{Al}$ LDH on the basis of TGA results is another possible factor for the enhanced flame retardancy. 


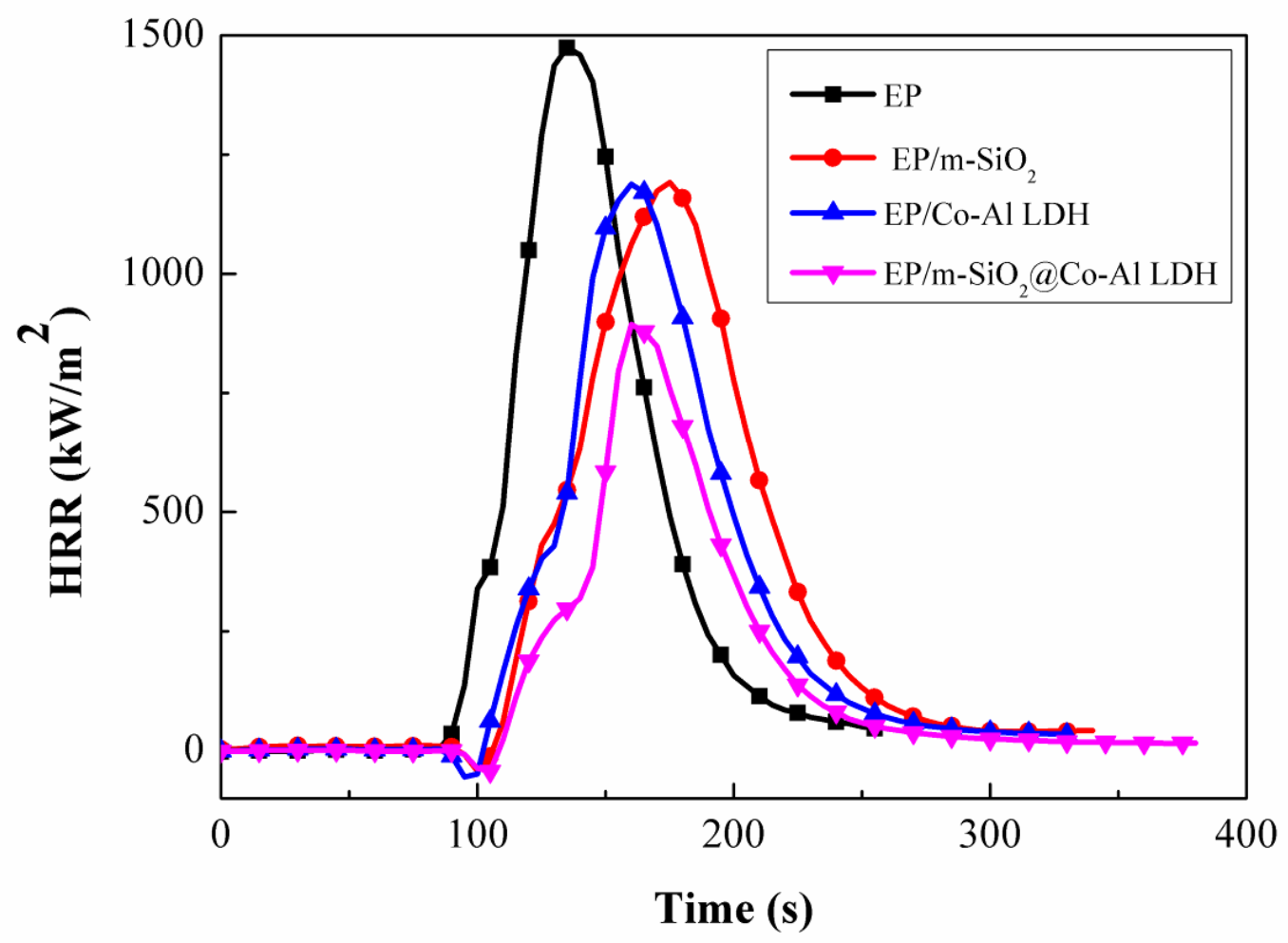

Figure 6. HRR curves of EP and its nanocomposites.

Table 2. Cone calorimetry data of EP and its nanocomposites.

\begin{tabular}{|c|c|c|c|c|c|c|}
\hline Sample & $\begin{array}{l}p H R R \\
\left(\mathrm{~kW} / \mathrm{m}^{2}\right)\end{array}$ & $\begin{array}{l}\text { THR } \\
\left(\mathrm{MJ} / \mathrm{m}^{2}\right)\end{array}$ & $\begin{array}{l}E H C \\
(\mathrm{MJ} / \mathrm{Kg}) \\
\end{array}$ & $\begin{array}{l}\text { MARHE } \\
\left(\mathrm{kW} / \mathrm{m}^{2}\right) \\
\end{array}$ & $\begin{array}{l}\text { TSR } \\
\left(\mathrm{m}^{2} / \mathrm{m}^{2}\right) \\
\end{array}$ & Char yield \% \\
\hline EP & 1473.4 & 87.8 & 24.1 & 434.2 & 2734.9 & $5.2 \%$ \\
\hline $\mathrm{EP} / \mathrm{m}-\mathrm{SiO}_{2}$ & 1191.2 & 96.5 & 26.4 & 383.8 & 2291.8 & $7.1 \%$ \\
\hline EP/Co-Al LDH & 1188.1 & 84.3 & 23.8 & 421.6 & 2370.3 & $12.1 \%$ \\
\hline EP/m-SiO ${ }_{2} @ \mathrm{Co}-\mathrm{Al}$ LDH & 893.8 & 56.0 & 20.3 & 361.7 & 2085.2 & $20.7 \%$ \\
\hline
\end{tabular}

\subsection{Flame retardant mechanism}

To understand the flame-retardant mechanism, we studied the thermal conductivity, the char residues and the degradation products of EP and its nanocomposites. Figure 7 shows the thermal conductivity of the nanocomposites at different temperatures. The thermal conductivity of the EP/Co-AI LDH is around $0.4131 \mathrm{~W} / \mathrm{m} \cdot \mathrm{K}$ and it changes slightly with the increase of the temperature. As for the EP/m-SiO ${ }_{2} @ \mathrm{Co}-\mathrm{Al}$ LDH nanocomposite, the thermal conductivity decreases compared to the EP/Co-AI LDH $(0.4131 \mathrm{~W} / \mathrm{m} \cdot \mathrm{K})$ to $0.2789 \mathrm{~W} / \mathrm{m} \cdot \mathrm{K}$ with a 
filler concentration of $2 \mathrm{wt} \%$. It is suggested that heat diffusion was more difficult in the presence of $\mathrm{m}-\mathrm{SiO}_{2} @ \mathrm{Co}-\mathrm{Al}$ LDH. Combined with the BET results (Figures $3 \mathrm{C}$ and $\mathrm{D}$ ), m-SiO ${ }_{2} @$ Co-Al LDH with larger surface area makes the path length longer that the transfer of oxygen and combustible products was inhibited, leading to retarded heat and mass release. Therefore, it is reasonable to believe that the low thermal conductivity and the labyrinth effect contributed by m-SiO ${ }_{2} @ \mathrm{Co}-\mathrm{Al}$ LDH could lead to the better flame resistance.

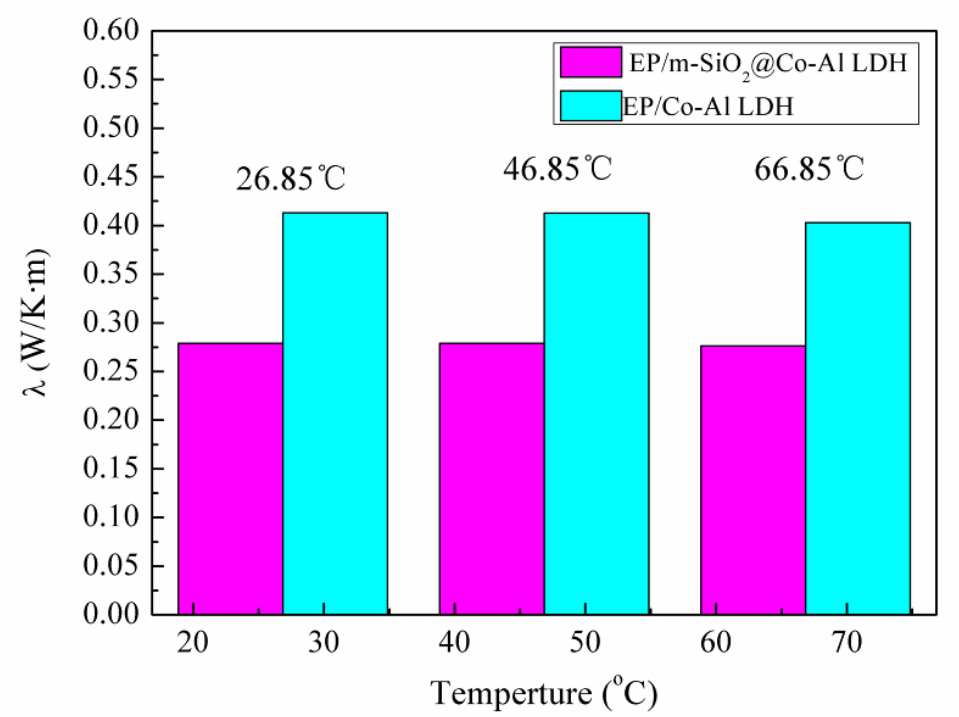

Figure 7. Thermal conductivity plot of the nanocomposites at different temperatures.

Figure 8A shows images of the char residues after cone calorimetry test, in which there are little residues left after thermal degradation of pure EP. The incorporation of m-SiO ${ }_{2} @ C o-A I L D H$ results in the significant improvement of the char yield, corresponding to the TGA results. To further explore the flame-retardant mechanism, Raman spectroscopy was utilized to characterize the structure and component of the residues. The Raman spectra of the residues of EP and EP/m-SiO ${ }_{2} @$ Co-Al LDH (Figure 8B) depicts two bands at $1356 \mathrm{~cm}^{-1}$ (D-band) and 1591 $\mathrm{cm}^{-1}$ (G-band), which are associated with the vibration of the carbon atoms in disordered graphite or glassy carbons and the carbon atoms in crystalline graphite., respectively. ${ }^{49}$ This result indicates the formation of the graphitized char during EP combustion, due to the catalysis of $\mathrm{m}-\mathrm{SiO}_{2} @ \mathrm{Co}-\mathrm{Al} \mathrm{LDH} .{ }^{50}$ As well known, the graphitized char is more conducive to suppress the diffusion of heat and mass during pyrolysis than disordered graphite or glassy carbons, which is ascribed to its higher thermal stability and compactness. Moreover, Figures $8 \mathrm{C}, \mathrm{D}$ show the typical microstructure of the residues of EP and EP/m-SiO ${ }_{2} @ \mathrm{Co}-\mathrm{Al} \mathrm{LDH}$ nanocomposite. It is clearly found that a continuous and cohesive char surface is formed after the EP/m-SiO $\mathrm{O}_{2} @ \mathrm{Co}-\mathrm{Al}$ $\mathrm{LDH}$ nanocomposite combustion. The residue with a more cohesive and compact layer is beneficial for the inhibition of the heat, mass and oxygen exchange, thereby improving the flame retardancy. 


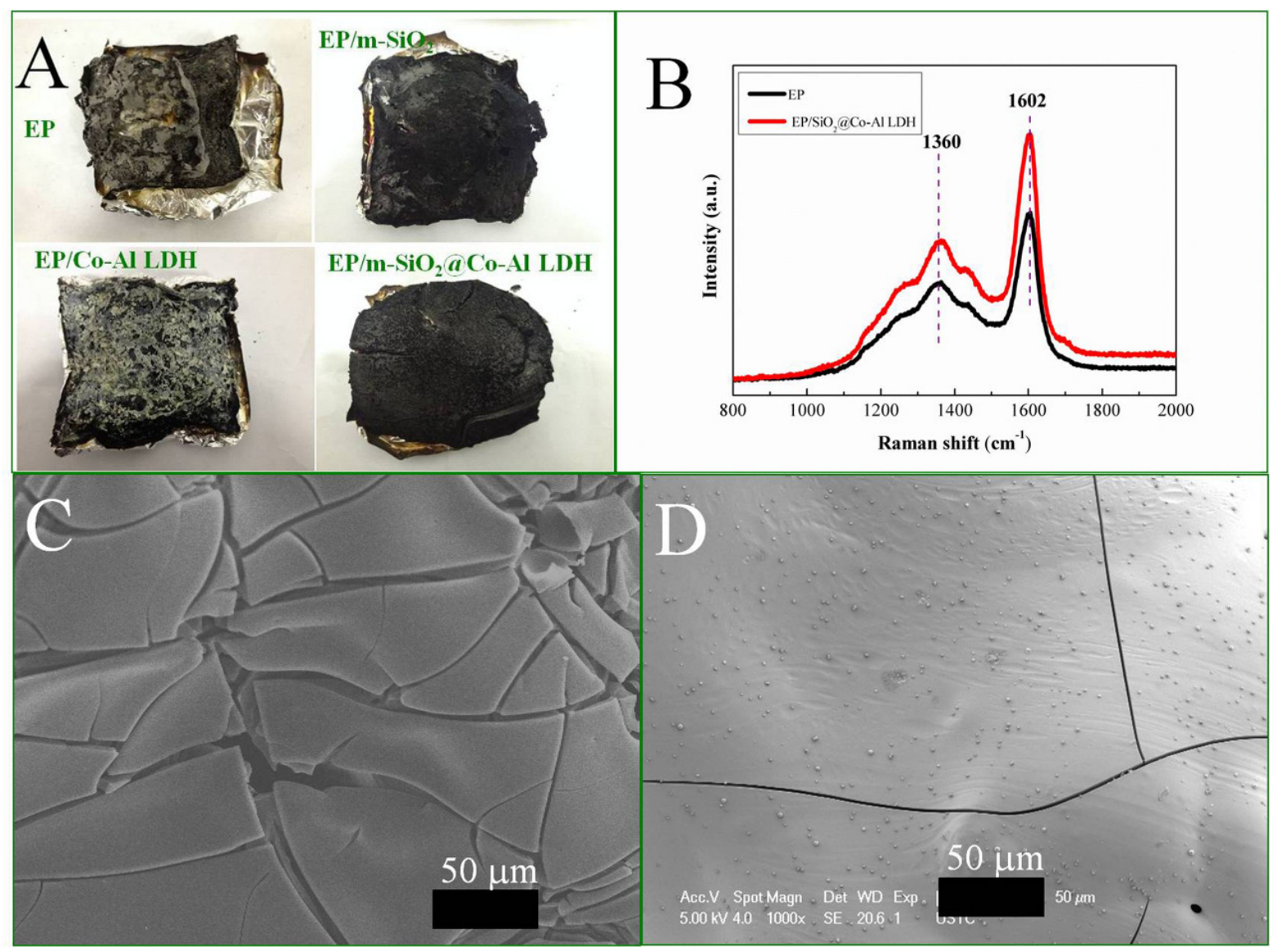

Figure 8. Digital photos (A) and Raman spectra (B) of the residues from EP and its

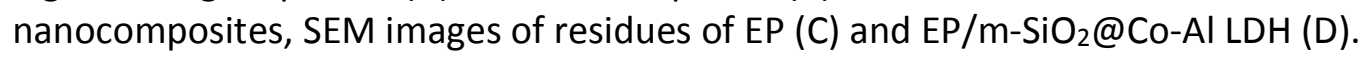

It is well-known that the pyrolysis products act as a key role in the flame-retardant performance of polymers. For the purpose of understanding the flame-retardant mechanism of the EP nanocomposites, the DP-MS tool was used to analyze the pyrolysis products. Figure 9 depicts the total ion current (TIC) chromatogram of EP and EP/m-SiO ${ }_{2} @$ Co-AI LDH nanocomposite, and El-MS spectra corresponding to the TIC peaks with the maximum intensity. The pyrolysis fragment ions with the molecular weight of $x$ are labelled as $M x$ and identified in Figure 10. For pure EP, the strong peak at $255 \mathrm{~m} / \mathrm{z}$ corresponds to $\mathrm{C}_{17} \mathrm{H}_{19} \mathrm{O}_{2}$. Also, the peaks at $269 \mathrm{~m} / \mathrm{z}, 213$ $\mathrm{m} / \mathrm{z}, 197 \mathrm{~m} / \mathrm{z}$ and $135 \mathrm{~m} / \mathrm{z}$ can be assigned to the pyrolysis products of $\mathrm{C}_{17} \mathrm{H}_{21} \mathrm{~N}_{2} \mathrm{O}, \mathrm{C}_{14} \mathrm{H}_{13} \mathrm{O}_{2}$, $\mathrm{C}_{15} \mathrm{H}_{18}$, and $\mathrm{C}_{9} \mathrm{H}_{11} \mathrm{O}$, Additionally, some fragment ions can regroup to produce new products in high temperature. Such as, the benzene and aniline reconstitute to form carbazole $(166 \mathrm{~m} / \mathrm{z})$, and the recombination between carbazole and benzene reconstitute generates a few polycyclic aromatic hydrocarbons $(497 \mathrm{~m} / \mathrm{z})$. In contrast, the main fractions in the degradation products of the EP/m-SiO $@$ @Co-Al LDH include $\mathrm{C}_{14} \mathrm{H}_{13} \mathrm{O}_{2}(213 \mathrm{~m} / \mathrm{z})$, which is with lower carbon numbers than that of neat EP. Actually, previous literatures reported that solid acids can catalyze the degradation of polymer, which results in the formation of pyrolysis products with lower carbon numbers, and the degradation products with lower carbon numbers could be easily catalyzed carbonization in the presence of metal oxides. ${ }^{51-52} \mathrm{~m}-\mathrm{SiO}_{2}$ has been reported to be a most 
efficient solid acid for catalytic degradation of polymer due to the presence of many acid sites. ${ }^{53-54}$ In this work, carbon numbers of pyrolysis products from the EP/m-SiO ${ }_{2} @ C o-A I L D H$ composite is also decreased compared with that of EP. Thus, this undoubtedly results from the catalytic degradation effect for $\mathrm{EP}$ by $\mathrm{m}-\mathrm{SiO}_{2} \cdot{ }^{53-54} \mathrm{Also}$, degradation products with lower carbon numbers could extend contacting time of with metal oxides catalyst under the labyrinth effect of $\mathrm{m}-\mathrm{SiO}_{2}$. With different Co catalysts, Gong et al., used a simple method to synthesize carbon nanospheres through the carbonization of polystyrene. ${ }^{55}$ Therefore, it is reasonable to believe that the enhanced flame resistant property for EP/m-SiO ${ }_{2} @ \mathrm{Co}-\mathrm{Al}$ LDH is attributed to the synergism of $\mathrm{m}-\mathrm{SiO}_{2}$ and $\mathrm{Co}-\mathrm{Al} \mathrm{LDH}$. In view of the results of the volatile pyrolysis fragment ions, the mechanism for the improved fire resistant property of EP/m-SiO ${ }_{2} @ \mathrm{Co}-\mathrm{Al} L D H$ nanocomposite is explained as follow. During the combustion process, $\mathrm{m}-\mathrm{SiO}_{2}$ with catalytic activity leads to the formation of pyrolysis products with lower carbon numbers, which can be easily catalyzed carbonization in the presence of metal oxides. Meanwhile, Co-AI LDH can catalyze carbonization of degradation products. Moreover, $\mathrm{m}-\mathrm{SiO}_{2}$ plays as a barrier which can absorb degraded products to extend contacting time of with metal compound catalyst. Furthermore, the degraded products are dehydrogenated and catalytically converted into char by the combination of $\mathrm{m}-\mathrm{SiO}_{2}$ labyrinth effect and Co-Al $\mathrm{LDH}$ catalysis effect.
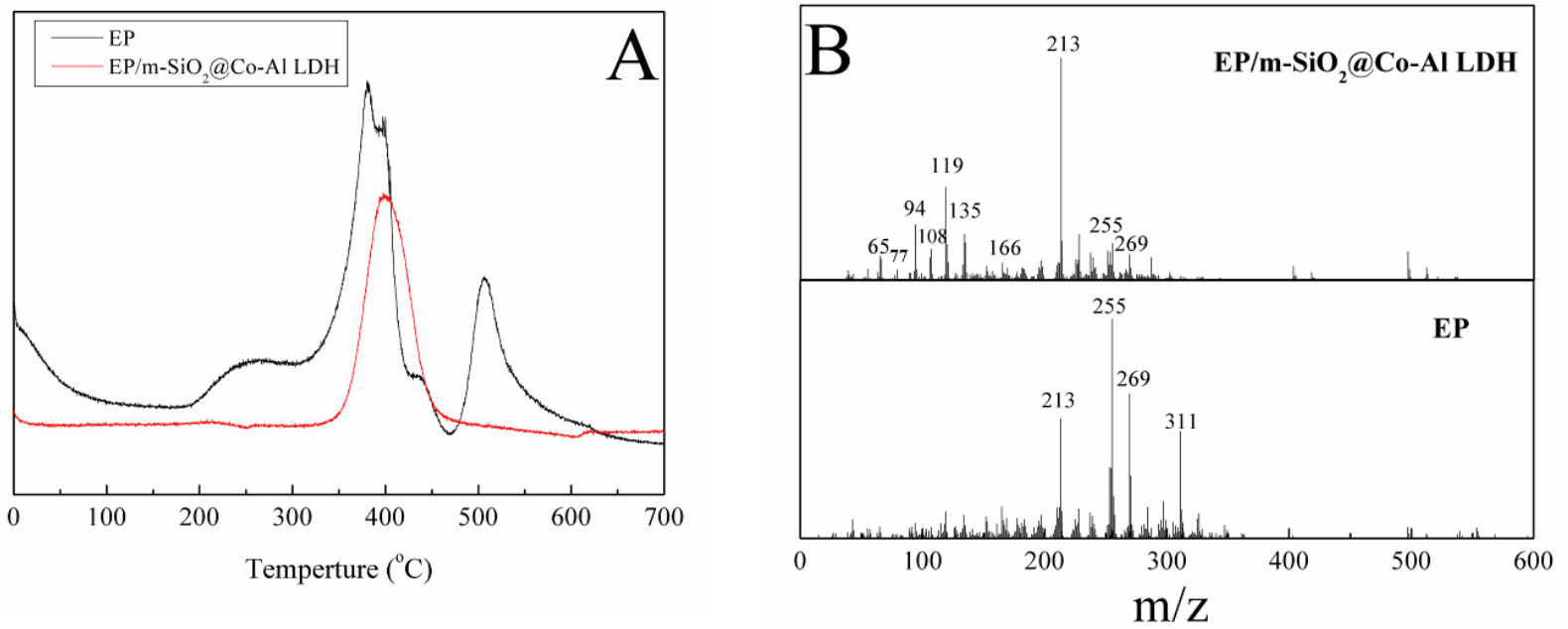

Figure 9. Total ion current (TIC) curves (A) of the decomposition process of EP and $\mathrm{EP} / \mathrm{m}-\mathrm{SiO}_{2} @ \mathrm{Co}-\mathrm{Al} \mathrm{LDH}$, and El-MS spectra (B) of compounds evolved from EP and $\mathrm{EP} / \mathrm{m}-\mathrm{SiO}_{2} @ \mathrm{Co}-\mathrm{Al}$ LDH at the maximum of the peak in the TIC curves. 


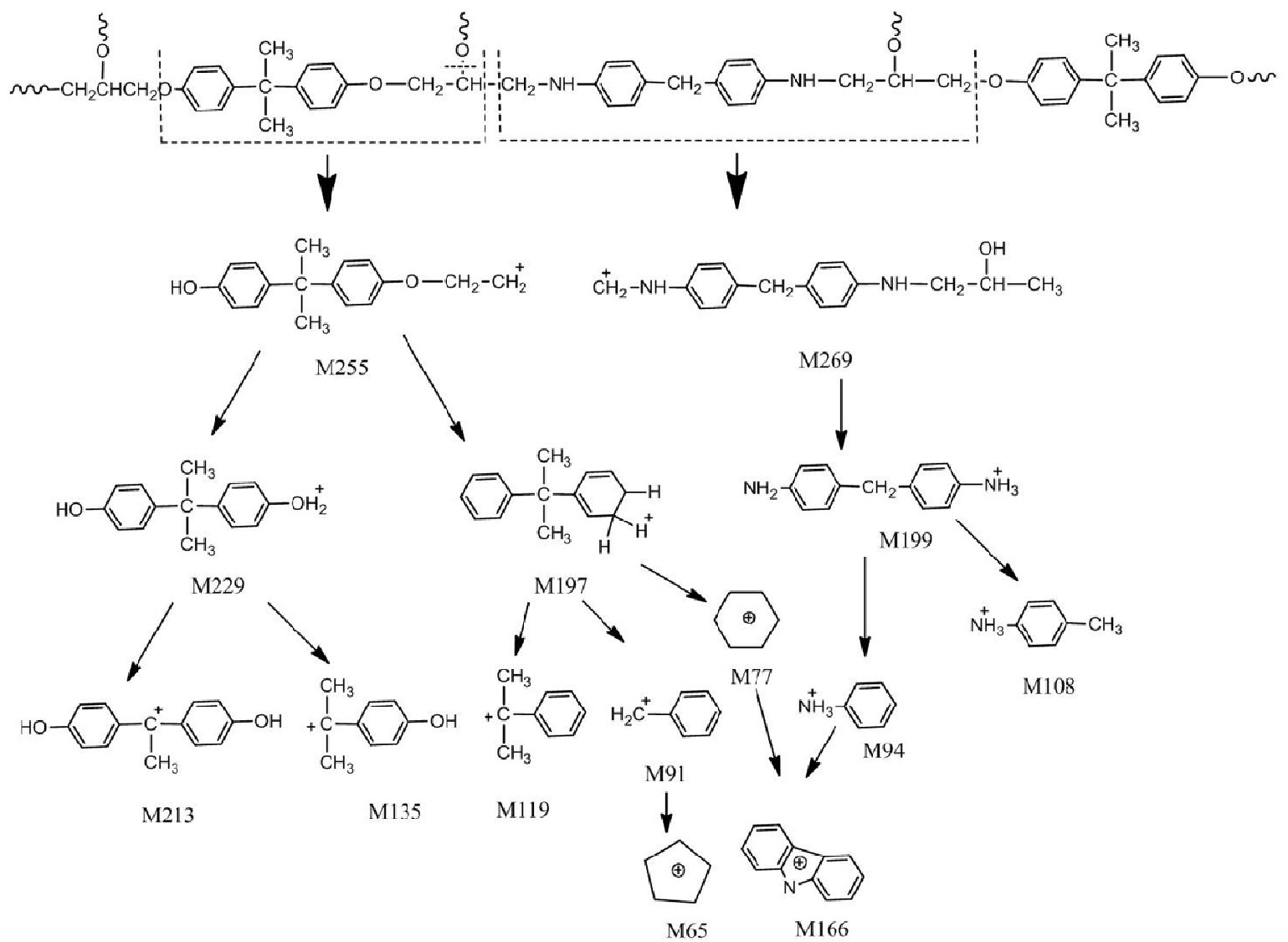

Figure 10. Simplified mass fragmentations of the EP/m-SiO ${ }_{2} @$ Co-Al LDH nanocomposite.

\section{Conclusions}

In conclusion, m-SiO $@$ @Co-Al LDH spheres were synthesized by ultrasound assisted direct layered assembly of Co-AI LDH nanosheets on the surface of $\mathrm{m}-\mathrm{SiO}_{2}$ spheres, and its composition and structure was identified by XRD, BET and XPS. The morphological characterization showed that, owning to the electric potential difference between $\mathrm{m}-\mathrm{SiO}_{2}$ and Co-Al LDH, m-SiO ${ }_{2} @$ Co-Al LDH exhibited that m-SiO ${ }_{2}$ spheres were packaged by the Co-Al LDH nanosheets. Incorporation of 2 wt\% m-SiO ${ }_{2} @ \mathrm{Co}-\mathrm{Al}$ LDH into EP led to the increase of the char yield and the decrease of DTG peak value. Moreover, the pHRR, THR, EHC, TSR and MAHRE values for $\mathrm{EP} / \mathrm{m}-\mathrm{SiO}_{2} @ \mathrm{Co}$-Al LDH were obviously reduced. A plausible flame-retardant mechanism was speculated based on the analyses of thermal conductivity, char residue and pyrolysis fragments. $\mathrm{m}-\mathrm{SiO}_{2}$ plays as a mass and heat barrier to prevent the diffusion of heat and the spread of the pyrolysis products, and hence prolong the contact time between the pyrolysis products and the Co-AI LDH catalyst. The significant reduction of the fire hazard was primarily due to the synergistic action between the labyrinth effect of $\mathrm{m}$ - $\mathrm{SiO}_{2}$ and the catalytic effect of Co-Al LDH. 


\section{Acknowledgements}

The work was financially supported by the National Natural Science Foundation of China (21374111) and the National Basic Research Program of China (973 Program) (2012CB719701).

\section{References}

1. Corma, A. From Microporous to Mesoporous Molecular Sieve Materials and Their Use in Catalysis. Chem. Rev. 1997, 97, 2373-2419.

2. Deng, Y. H.; Cai, Y.; Sun, Z. K.; Liu, J.; Liu, C.; Wei, J.; Li, W.; Liu, C.; Wang, Y.; Zhao, D. Y. Multifunctional Mesoporous Composite Microspheres with Well-Designed Nanostructure: A Highly Integrated Catalyst System. J. Am. Chem. Soc. 2010, 132, 8466-8473.

3. Sun, Z. K.; Deng, Y. H.; Wei, J.; Gu, D.; Tu, B.; Zhao, D. Y. Hierarchically Ordered Macro-/Mesoporous Silica Monolith: Tuning Macropore Entrance Size for Size-Selective Adsorption of Proteins. Chem. Mater. 2011, 23, 2176-2184.

4. Yang, H. F.; Shi, Q. H.; Tian, B. Z.; Xie, S. H.; Zhang, F. Q.; Yan, Y.; Tu, B.; Zhao, D. Y. A Fast Way for Preparing Crack-Free Mesostructured Silica Monolith. Chem. Mater. 2003, 15, 536-541.

5. Park, S. C.; Ito, T.; Higgins, D. A. Single Molecule Tracking Studies of Flow-Aligned Mesoporous Silica Monoliths: Aging-Time Dependence of Pore Order. J. Phys. Chem. B 2013, $117,4222-4230$.

6. Xue, C. F.; Wang, J. X.; Tu, B.; Zhao, D. Y. Hierarchically Porous Silica with Ordered Mesostructure from Confinement Self-Assembly in Skeleton Scaffolds. Chem. Mater. 2010, 22, 494-503.

7. Suzuki, N.; Kiba, S.; Yamauchi, Y. Fabrication of Mesoporous Silica/Polymer Composites through Solvent Evaporation Process and Investigation of Their Excellent Low Thermal Expansion Property. Phys. Chem. Chem. Phys. 2011, 13, 4957-4962.

8. Kiba, S.; Suzuki, N.; Okawauchi, Y.; Yamauchi, Y. Prototype of Low Thermal Expansion Materials: Fabrication of Mesoporous Silica/Polymer Composites with Densely Filled Polymer inside Mesopore Space. Chem. - Asian J. 2010, 5, 2100-2105.

9. Nguyen, T. Q.; Wu, J. J.; Doan, V.; Schwartz, B. J.; Tolbert, S. H. Control of Energy Transfer in Oriented Conjugated Polymer-Mesoporous Silica Composites. Science 2000, 288, 652-656.

10. Wang, S.; Liang, R.; Wang, B.; Zhang, C. Reinforcing Polymer Composites with Epoxide-Grafted Carbon Nanotubes. Nanotechnology 2008, 19, 085710.

11. Liu, M. X.; Guo, B. C.; Du, M. L.; Lei, Y. D.; Jia, D. M. Natural Inorganic Nanotubes Reinforced Epoxy Resin Nanocomposites. J. Polym. Res. 2008, 15, 205-212.

12. Koerner, H.; Hampton, E.; Dean, D.; Turgut, Z.; Drummy, L.; Mirau, P.; Vaia, R. Generating Triaxial Reinforced Epoxy/Montmorillonite Nanocomposites with Uniaxial Magnetic Fields. Chem. Mater. 2005, 17, 1990-1996. 
13. Abdalla, M.; Dean, D.; Theodore, M.; Fielding, J.; Nyairo, E.; Price, G. Magnetically Processed Carbon Nanotube/Epoxy Nanocomposites: Morphology, Thermal, and Mechanical Properties. Polymer 2010, 51, 1614-1620.

14. Zhang, F. A.; Lee, D. K.; Pinnavaia, T. J. PMMA/Mesoporous Silica Nanocomposites: Effect of Framework Structure and Pore Size on Thermomechanical Properties. Polym. Chem. 2010, 1, 107-113.

15. Qian, Y.; Wei, P.; Jiang, P. K.; Li, Z.; Yan, Y. G.; Ji, K. J. Aluminated Mesoporous Silica as Novel High-Effective Flame Retardant in Polylactide. Compos. Sci. Technol. 2013, 82, 1-7.

16. Zhao, Y. F.; He, S.; Wei, M.; Evans, D. G.; Duan, X. Hierarchical Films of Layered Double Hydroxides by Using a Sol-Gel Process and Their High Adaptability in Water Treatment. Chem. Commun. 2010, 46, 3031-3033.

17. Chen, C. P.; Gunawan, P.; Xu, R. Self-Assembled Fe304-Layered Double Hydroxide Colloidal Nanohybrids with Excellent Performance for Treatment of Organic Dyes in Water. J. Mater. Chem. 2011, 21, 1218-1225.

18. Yu, X. Y.; Luo, T.; Jia, Y.; Xu, R. X.; Gao, C.; Zhang, Y. X.; Liu, J. H.; Huang, X. J. Three-Dimensional Hierarchical Flower-Like Mg-Al-Layered Double Hydroxides: Highly Efficient Adsorbents for As(V) and Cr(VI) Removal. Nanoscale 2012, 4, 3466-3474.

19. Wang, X.; Zhou, S.; Xing, W. Y.; Yu, B.; Feng, X. M.; Song, L.; Hu, Y. Self-Assembly of Ni-Fe Layered Double Hydroxide/Graphene Hybrids for Reducing Fire Hazard in Epoxy Composites. J. Mater. Chem. A 2013, 1, 4383-4390.

20. Shao, M. F.; Ning, F. Y.; Zhao, J. W.; Wei, M.; Evans, D. G.; Duan, X. Preparation of $\mathrm{Fe}_{3} \mathrm{O}_{4} @ \mathrm{SiO}_{2} @$ Layered Double Hydroxide Core-Shell Microspheres for Magnetic Separation of Proteins. J. Am. Chem. Soc. 2012, 134, 1071-1077.

21. Hu, J. L.; Yang, Q. H.; Lin, H.; Ye, Y. P.; He, Q.; Zhang, J. N.; Qian, H. S. Mesoporous Silica Nanospheres Decorated with CdS Nanocrystals for Enhanced Photocatalytic and Excellent Antibacterial Activities. Nanoscale 2013, 5, 6327-6332.

22. Teng, Z. G.; Sun, C. H.; Su, X. D.; Liu, Y.; Tang, Y. X.; Zhao, Y. N.; Chen, G. T.; Yan, F.; Yang, N. N.; Wang, C. Y.; Lu, G. M. Superparamagnetic High-Magnetization Composite Spheres with Highly Aminated Ordered Mesoporous Silica Shell for Biomedical Applications. J. Mater. Chem. B 2013, 1, 4684-4691.

23. Wu, Q. L.; Olafsen, A.; Vistad, O. B.; Roots, J.; Norby, P. Delamination and Restacking of A Layered Double Hydroxide with Nitrate as Counter Anion. J. Mater. Chem. 2005, 15, 4695-4700.

24. Wang, L.; Wang, D.; Dong, X. Y.; Zhang, Z. J.; Pei, X. F.; Chen, X. J.; Chen, B. A.; Jin, J. A. Layered Assembly of Graphene Oxide and Co-Al Layered Double Hydroxide Nanosheets as Electrode Materials for Supercapacitors. Chem. Commun. 2011, 47, 3556-3558.

25. Zhu, Y. F.; Shi, J. L.; Shen, W. H.; Dong, X. P.; Feng, J. W.; Ruan, M. L.; Li, Y. S. Stimuli-Responsive Controlled Drug Release from a Hollow Mesoporous Silica Sphere/Polyelectrolyte Multilayer Core-Shell Structure. Angew. Chem., Int. Ed. 2005, 44, 
5083-5087.

26. Bao, C. L.; Guo, Y. Q.; Song, L.; Kan, Y. C.; Qian, X. D.; Hu, Y. In Situ Preparation of Functionalized Graphene Oxide/Epoxy Nanocomposites with Effective Reinforcements. J. Mater. Chem. 2011, 21, 13290-13298.

27. Das, G.; Karak, N. Thermostable and Flame Retardant Mesua Ferrea L. Seed Oil Based Non-Halogenated Epoxy Resin/Clay Nanocomposites. Prog. Org. Coat. 2010, 69, 495-503.

28. Yan, N.; Wang, F.; Zhong, H.; Li, Y.; Wang, Y.; Hu, L.; Chen, Q. W. Hollow Porous $\mathrm{SiO}_{2}$ Nanocubes Towards High-performance Anodes for Lithium-Ion Batteries. Sci. Rep. 2013, 3, DOI: 10.1038/srep01568.

29. Liu, Z. P.; Ma, R. Z.; Osada, M.; Iyi, N.; Ebina, Y.; Takada, K.; Sasaki, T. Synthesis, Anion Exchange, and Delamination of Co-Al Layered Double Hydroxide: Assembly of the Exfoliated Nanosheet/Polyanion Composite Films and Magneto-Optical Studies. J. Am. Chem. Soc. 2006, $128,4872-4880$.

30. Zhang, W. F.; Ma, C.; Fang, J. H.; Cheng, J. P.; Zhang, X. B.; Dong, S. R.; Zhang, L. Asymmetric Electrochemical Capacitors with High Energy and Power Density Based on Graphene/Coal-LDH and Activated Carbon Electrodes. RSC Adv. 2013, 3, 2483-2490.

31. Jiang, S. D.; Yao, Q. Z.; Zhou, G. T.; Fu, S. Q. Fabrication of Hydroxyapatite Hierarchical Hollow Microspheres and Potential Application in Water Treatment. J. Phys. Chem. C 2012, 116, 4484-4492.

32. Kresge, C. T.; Leonowicz, M. E.; Roth, W. J.; Vartuli, J. C.; Beck, J. S. Ordered Mesoporous Molecular-Sieves Synthesized by a Liquid-Crystal Template Mechanism. Nature 1992, 359, 710-712.

33. Yan, N.; Chen, Q. W.; Wang, F.; Wang, Y.; Zhong, H.; Hua, L. High Catalytic Activity for CO Oxidation of $\mathrm{CO}_{3} \mathrm{O}_{4}$ Nanoparticles in $\mathrm{SiO}_{2}$ Nanocapsules. J. Mater. Chem. A 2013, 1, 637-643.

34. Fan, G. L.; Wang, H.; Xiang, X.; Li, F. Co-Al Mixed Metal Oxides/Carbon Nanotubes Nanocomposite Prepared via a Precursor Route and Enhanced Catalytic Property. J. Solid State Chem. 2013, 197, 14-22.

35. Li, J.; Tang, S. B.; Lu, L.; Zeng, H. C. Preparation of Nanocomposites of Metals, Metal Oxides, and CarbonNanotubes via Self-Assembly. J. Am. Chem. Soc. 2007, 129, 9401-9409.

36. Shi, J. Y.; Yao, Q. Z.; Li, X. M.; Zhou, G. T.; Fu, S. Q. Formation of Asymmetrical Structured Silica Controlled by a Phase Separation Process and Implication for Biosilicification. PLoS One 2013, 8, e61164.

37. Lin, H. Y.; Chen, Y. W. Preparation of Spherical Hexagonal Mesoporous Silica. J. Porous Mater. 2005, 12, 95-105.

38. Hukkamaki, J.; Pakkanen, T. T. Amorphous Silica Materials Prepared by Neutral Templating Route Using Amine-Terminated Templates. Microporous Mesoporous Mater. 2003, 65, 189-196.

39. Tsutsumi, K.; Kurata, N.; Takata, E.; Furuichi, K.; Nagano, M.; Tabata, K. Silicon 
Semiconductor-Assisted Bronsted Acid-Catalyzed Dehydration: Highly Selective Synthesis of 5-Hydroxymethylfurfural from Fructose under Visible Light Irradiation. Appl. Catal., B 2014, 147, 1009-1014.

40. Yan, X. Q.; Wang, X. J.; Tang, Y.; Ma, G. C.; Zou, S. H.; Li, R. H.; Peng, X. G.; Dai, S.; Fan, J. Unusual Loading-Dependent Sintering-Resistant Properties of Gold Nanoparticles Supported within Extra-large Mesopores. Chem. Mater. 2013, 25, 1556-1563.

41. Wang, D. Y.; Das, A.; Costa, F. R.; Leuteritz, A.; Wang, Y. Z.; Wagenknecht, U.; Heinrich, G. Synthesis of Organo Cobalt Aluminum Layered Double Hydroxide via a Novel Single-Step Self-Assembling Method and Its Use as Flame Retardant Nanofiller in PP. Langmuir 2010, 26, 14162-14169.

42. Hong, N. N.; Song, L.; Wang, B. B.; Stec, A. A.; Hull, T. R.; Zhan, J.; Hu, Y. Co-Precipitation Synthesis of Reduced Graphene Oxide/NiAl-Layered Double Hydroxide Hybrid and Its Application in Flame Retarding Poly(Methyl Methacrylate). Mater. Res. Bull. 2014, 49, 657-664.

43. Cheng, K. C.; Yu, C. B.; Guo, W. J.; Wang, S. F.; Chuang, T. H.; Lin, Y. H. Thermal Properties and Flammability of Polylactide Nanocomposites with Aluminum Trihydrate and Organoclay. Carbohydr. Polym. 2012, 87, 1119-1123.

44. Laufer, G.; Kirkland, C.; Cain, A. A.; Grunlan, J. C. Clay-Chitosan Nanobrick Walls: Completely Renewable Gas Barrier and Flame-Retardant Nanocoatings. ACS Appl. Mater. Interfaces 2012, 4, 1643-1649.

45. Kashiwagi, T.; Grulke, E.; Hilding, J.; Groth, K.; Harris, R.; Butler, K.; Shields, J.; Kharchenko, S.; Douglas, J. Thermal and Flammability Properties of Polypropylene/Carbon Nanotube Nanocomposites. Polymer 2004, 45, 4227-4239.

46. Qian, X. D.; Yu, B.; Bao, C. L.; Song, L.; Wang, B. B.; Xing, W. Y.; Hu, Y.; Yuen, R. K. K. Silicon Nanoparticle Decorated Graphene Composites: Preparation and Their Reinforcement on the Fire Safety and Mechanical Properties of Polyurea. J. Mater. Chem. A 2013, 1, 9827-9836.

47. Cain, A. A.; Nolen, C. R.; Li, Y. C.; Davis, R.; Grunlan, J. C. Phosphorous-Filled Nanobrick Wall Multilayer Thin Film Eliminates Polyurethane Melt Dripping and Reduces Heat Release Associated with Fire. Polym. Degrad. Stab. 2013, 98, 2645-2652.

48. Hoffmann, F.; Cornelius, M.; Morell, J.; Froba, M. Silica-Based Mesoporous Organic-Inorganic Hybrid Materials. Angew. Chem., Int. Ed. 2006, 45, 3216-3251.

49. Fang, M.; Wang, K. G.; Lu, H. B.; Yang, Y. L.; Nutt, S. Single-Layer Graphene Nanosheets with Controlled Grafting of Polymer Chains. J. Mater. Chem. 2010, 20, 1982-1992.

50. Lespade, P.; Aljishi, R.; Dresselhaus, M. S. Model for Raman-Scattering from Incompletely Graphitized Carbons. Carbon 1982, 20, 427-431.

51. Song, R. J.; Jiang, Z. W.; Bi, W. G.; Cheng, W. X.; Lu, J.; Huang, B. T.; Tang, T. The Combined Catalytic Action of Solid Acids with Nickel for the Transformation of Polypropylene into Carbon Nanotubes by Pyrolysis. Chem. - Eur. J. 2007, 13, 3234-3240.

52. Song, R. J.; Jiang, Z. W.; Yu, H. O.; Liu, J.; Zhang, Z. J.; Wang, Q. W.; Tang, T. Strengthening 
Carbon Deposition of Polyolefin Using Combined Catalyst as a General Method for Improving Fire Retardancy. Macromol. Rapid Commun. 2008, 29, 789-793.

53. Eren, E.; Guney, M.; Eren, B.; Gumus, H. Performance of Layered Birnessite-Type Manganese Oxide in the Thermal-Catalytic Degradation of Polyamide 6. Appl. Catal., B 2013, 132, 370-378.

54. Karami, C.; Ahmadian, H.; Nouri, M.; Jamshidi, F.; Mohammadi, H.; Ghodrati, K.; Farrokhi, A.; Hamidi, Z. A Novel Method for Synthesis of Cobalt Manganese Oxide Nano Catalysts as a Recyclable Catalyst for the Synthesis of Some Bis (Indolyl) Methane Derivatives. Catal. Commun. 2012, 27, 92-96.

55. Gong, J.; Liu, J.; Chen, X. C.; Wen, X.; Jiang, Z. W.; Mijowska, E.; Wang, Y. H.; Tang, T. Synthesis, Characterization and Growth Mechanism of Mesoporous Hollow Carbon Nanospheres by Catalytic Carbonization of Polystyrene. Microporous Mesoporous Mater. 2013, 176, 31-40. 